\title{
¿Es factible un diccionario de adverbios en -mente? ${ }^{1}$
}

\author{
Susana Azpiazu Torres \\ Universidad de Salamanca
}

Una de las tareas que, en opinión de algunos lingüistas, queda aún por realizar en el estudio de la lengua española es la elaboración de un diccionario de adverbios en -mente. Este requerimiento se relaciona con el creciente interés con el que los lingüistas observan un fenómeno que se está desarrollando en la lengua y que, de alguna manera, se siente como característico del español del siglo XX: la profusión en varios niveles de la lengua del empleo de estos adverbios largos. A su estudio se han aproximado los lingüistas desde todas las disciplinas gramaticales; sin embargo, parece que la lexicografía no termina de comulgar plenamente con los útiles que la gramática le ha ido ofreciendo para el tratamiento de los adverbios en -mente, pues es un hecho la dificultad que encuentran los diccionarios para lematizar estos adverbios de una manera satisfactoria. Así, suele ser bastante frecuente que los lexicógrafos se sientan en la obligación de justificar tal o cual decisión adoptada respecto a los adverbios en -mente y que nunca los gramáticos encuentren satisfactorias estas decisiones. Ahora bien, la cuestión es si un diccionario general y uno de adverbios en -mente

1 En este artículo se presentan parte de las conclusiones a las que he llegado tras varios años de trabajo en mi tesis doctoral sobre los adverbios en -mente, gracias a una beca predoctoral de investigación de la Junta de Castilla y León. Además forma parte del proyecto de investigación Gramática de base léxica: el sintagma verbal en la gramática española (PB26-1277) que se lleva a cabo en el Departamento de Lengua Española de la Universidad de Salamanca.

2 Tomo esta terminología de G. Haensch (1997, 149 y sigs). El diccionario definitorio 
pueden prescindir de lo gramatical en sus descripciones y, sobre todo, si lo pueden hacer en el mismo grado. Para responder a esta pregunta se hace necesaria una atenta observación de los problemas de descripción que deben resolver tanto los diccionarios estándar ("definitorios" o "de uso" ) como uno que sólo recoja estas formaciones.

\section{ESTADO DE LA CUESTIÓN:}

1. 1. Ya Casares había llamado la atención sobre la necesidad de corregir las descripciones semánticas referidas a los adverbios en -mente en los diccionarios generales:

Empezaremos por hacer notar que la costumbre de llamar "adverbios de modo" a todos los acabados en -mente pudo estar justificada en un principio, es decir, mientras esta terminación no se había divorciado por completo del ablativo mens. Hoy esa denominación, aplicada indistintamente, no parece adecuada. (Casares: 1989, 322)

Casares distingue entre estos adverbios valores de modo, cantidad, tiempo, ordinales, locuciones conjuntivas, para concluir afirmando: "He aquí una consideración que, si se estima acertada, obligará al lexicógrafo a un estudio de los adverbios más detenido que el que se venía haciendo hasta ahora" (ibid.).

1. 2. Un trabajo de este tipo, el primer intento sistemático por definir con criterios lexicográficos un número bastante significativo de adverbios en -mente es el llevado a cabo por L. Santos $(1994)^{3}$. En es-

sería básicamente un diccionario de recepción (pasivo o descifrador), sin indicaciones suficientes de producción de enunciados lingüísticos, mientras que el diccionario de uso se caracterizaría por permitir ampliación paradigmática (sinónimos, antónimos), ampliación sintagmática (rección, colocaciones, valencias verbales, etc.) y frases-ejemplo.

3 Un trabajo anterior que se sitúa en una línea similar es la tesis doctoral de M. Azcárate (1992). En la última parte de su estudio se presenta un "diccionario funcional" con los adverbios en -mente aparecidos en el corpus con el que se ha trabajado y se establece una comparación entre este diccionario y el DRAE-84. Sin embargo, el alcance y la profundidad de análisis del trabajo de Santos supera en mucho este otro estudio.

4 Este término debe entenderse en el sentido en que lo emplea Halliday (1961, 272 y sigs.) como "escala de diferenciación", "profundidad en el detalle", etc. 
ta obra se analizan por vez primera los adverbios tal y como cabría hacerlo en un diccionario, con un grado de delicadeza $a^{4}$ en la descripción muy notable, puesto que se pretende aunar en él el máximo de información semántica y gramatical. Para llevar a cabo este trabajo el autor se enfrentó previamente con el problema decisionista de establecer los límites del repertorio (él lo denomina una "selección de adverbios"). Su criterio primero, desarrollado en el prólogo (pág. 7), es el que le hace concebir el diccionario como atesorador no tanto de significados como de posibilidades léxicas. Más adelante expone con mayor claridad cuáles son estos límites autoimpuestos:

impredecibilidad de la existencia del adverbio, impredecibilidad de su significado (en alguno de sus usos), pluralidad de acepciones siendo alguna de ellas no meramente calificativa modal, restricciones colocativas lingüísticamente relevantes, empleo típico en un género textual, pertenencia a alguna clase sintáctico-semántica especial (he tenido en cuenta, por ejemplo, datos como el poder actuar como adverbio oracional, el poseer capacidad de cohesión mediante anáfora, el no sobrepasar la categoría de 'subjunto', el poseer régimen, especialmente si el complemento regido puede reproducir hechos, el poseer capacidad de referencia deíctica extratextual, el poder actuar como cerca semántica...), el que pertenezca al metalenguaje, el que sea relacionable con adjetivos argumentales, etc. (p. 27)

Como puede apreciarse, los criterios que expone aquí Santos son de índole muy diversa. Incluyen cuestiones relacionadas con la productividad tanto léxica como semántica de los adverbios, con sus colocaciones sintagmáticas preferentes, con factores de índole estilística y con aspectos gramaticales en el más amplio sentido. El proyecto es, cuando menos, muy ambicioso, pues de alguna manera pretende abarcar todo lo que los adverbios en -mente tienen de lingüístico, es decir, de exponente de una categoría de la lengua, lo cual le exige el esfuerzo de abordar su estudio desde el mayor número de perspectivas posibles. No es en absoluto desdeñable el intento, ni los resultados a que llega el autor, que constituyen un primer paso hacia la consecución del tan

5 Drae (1992), Preámbulo, p. VII.

6 Datos tomados de Moreno Villanueva, J. A.: "La sufijación en -mente: su inclusión 
anhelado diccionario de adverbios en -mente. Sin embargo creemos, después de haber ensayado también por nuestra cuenta el desarrollo cabal de este mismo trabajo, que la propia ambición del proyecto termina por convertirse en el mayor obstáculo para su realización. Este hecho ha sido el que, en definitiva, nos ha conducido a formular la pregunta que encabeza el trabajo. Para poder responderla será preciso abordar primero los rasgos del objeto que son más pertinentes para la lexicografía, como son la predecibilidad/impredecibilidad del adverbio a partir del adjetivo (lo que justifica la pertinencia o no de su inclusión en el diccionario) y la productividad de -mente como formador de nuevos adverbios.

\section{PREDECIBILIDAD}

2. 1. La predecibilidad de los adverbios en -mente se plantea como problema explícito para los diccionarios generales a raíz de la decisión de la $21^{\text {a }}$ edición (1992) del Diccionario de la Real Academia de suprimir muchos de ellos, con el argumento de que se trataba de "entradas innecesarias" por predecibles a partir del significado del adjetivo correspondiente $^{5}$. A este criterio pueden hacérsele algunas objeciones: la primera es de orden estrictamente formal y se relaciona con el conflicto entre intereses lingüísticos y editoriales al que debe enfrentarse el lexicógrafo. Un estudio pormenorizado de los casos concretos revela la poca sistematicidad con que se ha llevado a cabo la labor de supresión anunciada en el prólogo. En efecto, en realidad esta supresión sólo ha sido efectiva en las primeras páginas del diccionario, concretamente las que van de la letra A a la D, donde faltan 312 de los 342 adverbios suprimidos con respecto a la edición anterior, la de 1984. Los otros 30 adverbios suprimidos se reparten entre el resto de las letras 6 . Este llamativo desequilibrio bastaría por sí sólo para hacernos desconfiar

en los diccionarios del español”, comunicación leída en el XIII Congreso Nacional de la Asociación Española de Lingüística Aplicada, Castellón, 26-28.4.95.

7 Es cierto que el conflicto editorial del lexicógrafo se vuelve especialmente agudo en el caso de los adverbios en -mente. D. Corbin (1982), que estudia el tratamiento que reciben los adverbios en -ment en el Nouveau Dictionnaire du Française Contempo- 
de los motivos pretendidamente lingüísticos que aduce el DrAE para la adopción de su criterio lexicográfico. Habría que pensar más bien que el motivo real que movió a la supresión de lemas fue una exigencia editorial, lo cual no sería en sí mismo censurable si no se lo intentara justificar con argumentos lingüísticos ${ }^{7}$.

2. 2. 1. Porque, yendo aún más lejos, lo que de verdad debe censurarse de esta decisión es la ligereza con que se adopta el criterio de la pretendida "predecibilidad" para llevarla a cabo. Un ejemplo de las dificultades que entraña este concepto lo ilustra el caso de claramente, uno de los muchos adverbios que se han suprimido en la edición de 1992. Este adverbio aparecía en la edición de 1984 definido como "adv. m. Con claridad". Es evidente que con este tipo de definiciones tan generales apenas se aporta ninguna novedad semántica con respecto a la base, el adjetivo claro, a. La definición es tan abstracta y abarcadora como el propio concepto de la "claridad". Desde este punto de vista, la supresión del adverbio estaría plenamente justificada. Ahora bien, siendo de verdad coherentes, si optamos por definir los adverbios en -mente de esta manera, habría que decidirse por suprimirlos todos sin excepción de los diccionarios, pues difícilmente hallaremos casos en los que el adjetivo de la base no tenga, en cualquiera de sus múltiples acepciones (que, por el contrario, sí suelen ser descritas con bastante minuciosidad), ni un sólo punto en común con el adverbio a que ha dado lugar. Si llevamos hasta sus últimas consecuencias el criterio seguido por la Academia, puede afirmarse rotundamente que todos los adverbios en -mente son predecibles a partir de sus bases.

2. 2. 2. Pero hay algo más: no es la paráfrasis propiamente dicha lo que de verdad falla en la definición de claramente del DRAE-84 (pues-

rain afirma a este respecto: "Le dilemme devant lequel se trouve le lexicographe est le suivant: ou il décrit adéquatement les faites linguistiques, et il ne peut pas respecter les contraintes éditoriales (nombre de pages, public visé, etc.); ou, s'il respecte ces contraintes, sa description est linguistiquement inadéquate" (p. 56).

8 Por el contrario, el Diccionario Salamanca (DS) incluye ambas, aunque, en mi opinión, se equivoca al establecer las marcas, puesto que mezcla dos niveles gramaticales diferentes, el semántico y el sintáctico. La primera definición, la que recogía el DRAE-84, aparece con la misma marca que teníamos allí: adv. $m$. (marca semántica), 
to que, como ya hemos señalado, su abstracta generalidad impide que pueda considerársela errada), sino la marca semántica $\mathrm{m} .=$ modo). $\mathrm{Y}$ no porque sea falso que el adverbio exprese el modo en que se lleva a cabo la acción, sino porque se omite otra de las posibles interpretaciones del lema, la que además es más frecuente en el habla: la de claramente como operador de la modalidad epistémica del hablante que incide sintáctica y semánticamente sobre el conjunto de la oración 8 . Es posible que esta segunda interpretación sea una especie de abstracción a partir de la primera definición, la de modo, pero en absoluto es necesario que sea así. Podría ser un sentido latente ya en el adjetivo de la base, aunque no en su primera acepción, sino en otra surgida en otro nivel de conceptualización 9 . En cualquier caso, para poder afirmar que una formación es predecible desde la base no basta con generalizar a partir de una de las acepciones de la unidad de origen, sino que hay que tener en cuenta todas las posibilidades semánticas del lema en cuestión, y eso es justamente lo que falta en el DrAE.

2. 3. 1. Al tratar el asunto de las acepciones de los adverbios en -mente acabamos de plantear la difícil pregunta de si realmente cada uno de los sentidos del adverbio puede ser interpretado a partir de los distintos significados del adjetivo-base o si, por el contrario, hay

mientras que para la segunda, la de modalidad epistémica, se opta por una marca sintáctica ( $a d v$. orac.). Este error es, por otra parte, bastante común y se explica por la tendencia a asociar inequívocamente ciertas funciones con ciertos significados. Por otra parte, Azcárate no parece haber comprendido el valor de modalidad del adverbio, pues lo confunde con la intensidad (op. cit., 201).

9 Por ejemplo, en las acepciones 9, 10 y 11 de claro, - $a$ : "9. Inteligible, fácil de comprender. $\| 10$. Evidente, cierto, manifiesto. $\| 11$. Expresado con lisura, sin rebozo, con libertad." Cfr. la postura de la primera edición del diccionario de M. Moliner para este caso concreto. En el DUE claramente es un sublema de claro, - $a$ (en la $1^{\mathrm{a}} \mathrm{ed}$., no ya en la $2^{\text {a }}$ de 1998 , vid. infra) y remite a él "en cualquiera de las acepciones figuradas" del adjetivo. En realidad, el adverbio también puede referirse a las acepciones no figuradas de la base, que es lo que sucedía en la definición del DRAE antes de ser suprimido el lema.

10 Es lo que sucedería con práctico-prácticamente, seguro-seguramente, justo-justamente, etc. Sin embargo, normalmente estas dislocaciones semánticas responden a un fenómeno histórico, de manera que siempre sería posible recuperar, aunque fuera en etapas de lengua anteriores, la acepción que el adverbio compartía con el adjetivo. 
que considerarlos evoluciones independientes a partir del adverbio ya formado. Por una parte, la constante conexión semántica entre el significado del adverbio y el del adjetivo nos inclinaría a defender lo primero, pero, por otra parte, es también un hecho que no existen adverbios en -mente para cada una de las acepciones de la base, lo cual apoyaría la segunda postura. Esta última es también la que defiende J. Casares cuando se proclama partidario de incluir en los diccionarios "todos los adverbios en -mente cuya existencia no ofrezca dudas", argumentando que el adverbio sufre una restricción semántica con respecto a los significados del adjetivo y que además puede llegar a independizarse semánticamente de él, adquiriendo así plena autonomía léxica ${ }^{10}$ (op. cit., 231).

2. 3. 2. En contra de esto podría aducirse ciertamente que la propia naturaleza del adverbio es la causa de que no puedan derivarse usos adverbiales de cada acepción particular del adjetivo ${ }^{11}$, además de que, por otra parte, llegados a un nivel de abstracción semántica como el adoptado para la definición de claramente mencionado en $\S 2$. 2. 1., no parece ya posible renunciar del todo a cualquier vinculación del adverbio con su base, explícita o implícita, es decir, recogida entre las acepciones del adjetivo o simplemente intuida por el hablante. Repárese además en un hecho muy característico de los adverbios en -mente y es que, si forman locución con una preposición, ésta suele ser la misma que rige el adjetivo de la base: junto con $\rightarrow$ juntamente con, proporcional $a \rightarrow$ proporcionalmente $a$, contrario $a \rightarrow$ contrariamente $a$.

2. 4. La cuestión que se dirime aquí ha sido tratada intensamente (y desde antiguo) por la especulación lingüística (cfr. el magnífico

11 Por ejemplo, parece difícil encontrar un contexto en que fuera posible claramente con el significado 7 que recoge el DrAE para el adjetivo: "Dícese del color no subido o no muy cargado de tinte. Azul CLARO, castaño CLARO".

12 En la teoría lingüística este problema se plantea desde Coseriu (1955 y 1957) en términos diferentes, No se trata de establecer una jerarquía semántica entre adjetivo y adverbio pues lo que opera en cada uno es el significado categorial, no el significado léxico. El significado categorial es el que caracteriza a las unidades léxicas en su empleo factual. La mayor o menor pertinencia de un adverbio en un contexto deter- 
resumen de posturas que hace González: 1997, 45 y sigs.), llevando una $u$ otra postura a planteamientos teóricos muy diferentes incluso en el seno de una misma escuela lingüística, como ha sido el caso en el generativismo entre transformacionalistas y lexicalistas. Sin embargo, la envergadura del problema no es igual para la teoría lingüística 12 que para la lexicografía, donde una decisión en un sentido o en otro adquiere unas dimensiones prácticas mucho más determinantes. La lexicografía no se plantea aquí la naturaleza lingüística de dos categorías de la lengua, ni su misión es establecer una relación de prioridad léxicogenética de una sobre la otra, sino que debe proponer un modelo de descripción que sea práctico, es decir, útil de acuerdo con sus propios propósitos. Para nosotros, una lematización satisfactoria (práctica, útil) es aquella que es capaz de representar la dependencia del adverbio respecto de su base, pero que a la vez tiene en cuenta la especificidad y variedad del significado adverbial. Una propuesta que ha sido formulada de distintas maneras en varias ocasiones 13 es la de incorporar los adverbios en -mente, como formas completas o mediante algún tipo de marca, como subentradas en la microestructura del adjetivo ${ }^{14}$; concretamente (y esto es ya nuestra propuesta concreta) junto a la acepción $\mathrm{o}$ acepciones de que se deriven los distintos significados del adverbio.

minado depende, no tanto del (de los) significado (s) de su lexema, como del "modo en que significa".

13 Por ej. en Moreno Villanueva (com. cit.) o Santos (op. cit, 7).

14 Ya hemos visto como, en su primera edición, el DUE adoptaba este procedimiento para claramente (no era, sin embargo, una actitud sistemática, pues otros adverbios se recogían al modo "clásico", como lemas independientes). Esta forma de lematizar se ha modificado ya en la segunda edición del DUE (1998). Ahora los adverbios en -mente adquieren en la macroestructura del diccionario la misma categoría y el mismo cuerpo de letra que los adjetivos de la base (cfr. el prólogo de la nueva edición, p. XIV).

15 Estas razones se vinculan al estatus morfológico de la unidad -mente. En nuestra opinión no es tan claro que pueda ser considerado un sufijo al mismo nivel que el resto de los sufijos de la lengua. Más bien sostenemos, con otros autores (Gregores 1960, Saporta 1990, Zagona 1990), que debería considerarse en serio la posibilidad de no observarlo como tal, sino como una unidad de descripción híbrida a medio camino 
De este modo no se tratarían estos adverbios como lemas independientes y se los vincularía íntimamente a la base, pero habría también un margen para detallar sus peculiaridades semánticas cuando estas difirieran en algo de la acepción del adjetivo. También por razones morfológicas ${ }^{15}$ parece ésta una solución muy adecuada para el español, más adecuada que, por ejemplo, para el francés, lengua en la que en ocasiones la referencia a la base se ha perdido, bien porque al adverbializarse el adjetivo ha mudado su forma, bien porque ha dejado de existir como forma viva en la lengua (ejemplo de lo primero sería constamment $(<$ constante); ejemplos de lo segundo, notamment o sciemment). Sin embargo, en esta lengua se ha aplicado ya el procedimiento que defendemos ${ }^{16}$, lo cual constituye un argumento a su favor.

Tomemos, para ejemplificar esta propuesta, uno de los adverbios que suelen esgrimirse como ejemplo de la no predecibilidad del adver-

entre las estrategias de composición y las de derivación (tampoco pensamos, como hacen Bello y Gregores, que se trate de formas frásticas) en proceso de convertirse en sufijo, pero sin haber completado este proceso plenamente. Frente a otros autores que han descrito el fenómeno pero no han presentado ningún término alternativo para él, hemos propuesto en otro lugar (XXVII Simposio de la Sociedad Española de Lingüística, Palma de Mallorca, 15-19. 12. 97) el término semisufijo para-mente. De esta manera creemos poder presentar de un modo más claro las diferencias morfológicas que separan la forma española de la francesa, que sí sería un auténtico sufijo. (Sobre la distinta evolución morfológica de -mente en las lenguas romances, cfr. Karlsson 1981).

16 Por ejemplo, en el Dictionnaire du Française Contemporain y en el Nouveau Dictionnaire du Française Contemporain, analizado por Corbin (art. cit.). Después de llamar la atención sobre los errores a que lleva este tipo de lematización y el modo en que pueden ser subsanados, este autor termina afirmando que los adverbios en -ment en francés son "des objects difficilement lexicographiables" (p. 56). Sin duda deben de serlo más que en español.

17 Tanto las acepciones del adjetivo como las del adverbio están tomadas directamente del DrAE-92. En realidad, no he hecho más que aunar ambas entradas en una sola.

18 No existe el tiempo sagrado sino el tiempo profano, ni el tiempo es vivido religiosamente sino vendido y comprado a precio de mercado - El Mundo, 11. 10. 94. Esta definición debería ampliarse, puesto que el adverbio se entiende también en el sentido respectual: $1 \mathrm{~b}$. 'por lo que respecta a lo religioso': Religiosamente no sé lo que pre- 
bio a partir del adjetivo: religiosamente. Su inclusión en la microestructura del adjetivo adquiriría esta forma en nuestro modelo ${ }^{17}$ :

2. 5. Constatamos así que la incorporación de los adverbios en -

\section{religioso, a}

Del lat. religiosus.

1. adj. Perteneciente o relativo a la religión o a los que la profesan. $\rightarrow$ 1a. -mente: adv. m. Con religión. 18

2. Que tiene religión, y particularmente que la profesa con celo.

3. Que ha profesado en una orden religiosa regular. /. t. c. s.

4. Fiel y exacto en el cumplimiento del deber.

$\rightarrow$ 4a. -mente: adv. m. Con puntualidad y exactitud. 19

5. Moderado, parco.

mente en los diccionarios pasa necesariamente por una correcta definición del adjetivo. Así, dependerá del grado de afinamiento del análisis, de los niveles semánticos que se distingan, en definitiva, del nivel de exhaustividad en la descripción lexicográfica del adjetivo, el que la definición del adverbio sea más o menos adecuada. Este hecho constituye el primer gran inconveniente para la elaboración del diccionario de adverbios en -mente, pues supone un cambio en la orientación y en el propio objeto de estudio: no es ya el adverbio como forma resultante

dicarán, pero humanamente son muy buenos - El Mundo, 31. 7. 94. Sintácticamente puede ser de incidencia verbal u oracional.

19 Todo ello después de pasar religiosamente por taquilla y apoquinar 135 dólares del ala (17. 000 pesetas). - El Mundo, 30. 7.94

20 Aunque Santos no indica en sus lemas la conexión del adverbio con el adjetivo de la base sino que trata los adverbios como unidades independientes, contempla ya en los prolegómenos de su estudio la posibilidad de que un diccionario "bien hecho" resuelva la descripción del adverbio en -mente mediante algún tipo de marca dispuesto en la acepción del adjetivo-base (op. cit., 29).

21 Que es el nivel lexicográfico de las acepciones de diccionario. Somos conscientes de que, de alguna manera, esta concepción falsea la realidad de los hechos lingüísticos. 
sino el adjetivo como forma originaria lo que da cuenta de las variantes adverbiales ${ }^{20}$, al menos en el nivel léxico-semántico que nos interesa considerar aquí 21 .

\section{PRODUCTIVIDAD}

3. 1. El segundo aspecto lexicográfico relacionado con los adverbios en -mente se refiere a la delimitación de las unidades que debería recoger el diccionario, cuestión íntimamente vinculada al problema de la productividad del semisufijo. Recordemos que Casares pretendía incluir en los diccionarios todos los adverbios cuya existencia "no debe ofrecer dudas", pero que el repertorio de Santos era, en sus propias palabras, una selección de acuerdo con determinados principios metodológicos. En efecto, la propuesta de Casares alberga en su misma formulación una infinidad de nuevas complicaciones teóricas, pues sensu stricto cualquier adverbio atestiguado en la lengua histórica (incluidos los hapax legomena) tiene una existencia real de la que no cabe dudar. Es decir, siguiendo a Casares, no cabría más elección que la de incorporar a los repertorios lexicográficos adverbios neológicos de creación única aunque atentasen contra la tendencia lexicogenética de la lengua, sancionando adverbios que en principio no contradicen en absoluto esta tendencia pero que, por razones ajenas al sistema, nadie ha creado nunca o no se los ha encontrado en ninguna cita. Deberían

En efecto, el significado léxico no "parte" del adjetivo hacia el adverbio, sino que se localiza en el lexema que es común a ambas categorías (el significado categorial, evidentemente, tampoco deriva del adjetivo, ya que este se entiende como actualización de las unidades léxicas en cada emisión de lengua). Pero, como hemos dicho en el apartado anterior, se trata sólo de una concepción que resulta útil (y, por tanto, se justifica) para los fines de la lexicografía.

22 Estos tres adverbios aparecen citados en J. A. Mayoral (1982, 38-39).

23 Citado en M. García-Page (1991, 152). Todos estos adverbios "anómalos" y muchos otros que podrían añadirse, contradicen en parte la pretensión de establecer leyes de restrición lexicogénica para los adverbios en -mente, como propone Moignet (1963). Tal vez, más que de leyes, habría que hablar de tendencias de creación o restricción que se vinculan a la propia naturaleza semántica de la categoría adverbial y a su grado de compatibilidad con los significados de los adjetivos.

24 Casares (op. cit., 321). 
entonces aparecer adverbios tan singulares como tuyamente, ellamente, inarrancablemente 22 o nadamente ${ }^{23}$, que además están atestiguados en las páginas de poetas muy autorizados de este siglo, como son, respectivamente, P. Salinas, R. Montesinos, Blas de Otero y C. Vallejo, pero habría que ignorar una forma tan natural al sistema, pero nunca citada (o no recogida en la literatura), como desaprensivamente ${ }^{24}$. De hecho, la Academia sigue también el criterio de autoridad cuando se trata de autores clásicos, pues no duda en recoger en su diccionario formas tan curiosas como asnalmente o escuderilmente, atestiguadas, hasta donde yo sé, una sola vez en toda la historia del español, en el Quijote de Cervantes ${ }^{25}$. El problema que la productividad de -mente plantea a los diccionarios no se agota en la creación fáctica de nuevos adverbios, sino que se refiere también a las enormes posibilidades expresivas que ofrece 26 . La Academia no resuelve propiamente este asunto, simplemente adopta un criterio de autoridad que es arbitrario y está mal definido. Las creaciones individuales, no normalizadas, no tienen cabida en sus páginas, a menos que haya sido una autoridad de la talla de Cervantes el autor de dichas creaciones.

3. 2. Establecer los límites que los adverbios en -mente deben guardar en el diccionario es, pues, una dificultad más que debe solventar el lexicógrafo. Para él se trata de una cuestión aporética, pues parte del hecho de que un diccionario no es capaz de dar cuenta de lo que esca-

25 El DUE, por su parte, no menciona asnalmente pero sí escuderilmente. En el DS no aparece ni uno ni otro.

26 Dice Casares (ibid.) que "la libertad que permite la lengua para la formación de esos adverbios compuestos es tan amplia que no cabe imaginar de antemano qué posibilidades se han realizado y cuáles no."

27 Ibid., XII. En realidad, no se puede decir que existan "diccionarios totales" del español, quizá lo más cercano a este concepto sean los "diccionarios de uso", que, por su parte, tampoco aspiran a ser exhaustivos en la recolección de las entradas, pues atienden a otro tipo de información, más gramatical. Por su parte, en los "diccionarios tesoro" (¿definitorios?) tal y como los concibe M. Pidal se plantea la necesidad de definir más precisamente bajo qué condiciones una voz se considera "autorizada", "de buen uso" o "de buena tradición".

28 Alvar Ezquerra $(1980,63)$. En otras palabras, el diccionario no puede fijarse más que en la norma, debe renunciar de antemano a la pretensión de describir el sistema, 
pa a la norma lingüística, y los adverbios en -mente son un exponente típico de esto. Menéndez Pidal expone esta cuestión en su prólogo al DGILE, pág. XIII:

todo lo que literariamente se escribe, como no sea una aberración puramente individual y extravagante, todo lo que se habla por una agrupación de la sociedad no totalmente inculta, debiera ser recogido en el diccionario, ora proceda del momento actual, ora venga de tiempos pasados. Pero la dificultad está en que esa doble recolección de cuanto se escribe y cuanto se habla es prácticamente imposible en esa totalidad deseada.

Esta imposibilidad se hace patente si lo que se quiere es hacer un "diccionario total" o un "diccionario del habla", en el sentido en que lo entiende Menéndez Pidal, pero no representaría un problema para lo que él llama un "diccionario tesoro", es decir, una "compilación de voces autorizadas por el uso de los buenos escritores o por la mejor tradición del pueblo"27. En este caso sólo decide la "autoridad", sea lo que sea este concepto para la lengua. Casares, con su llamada a la exhaustividad en la descripción de los adverbios en -mente, plantea al lexicógrafo la paradoja de intentar ser descriptivo, cuando por definición un diccionario sólo puede ser fijación y normalización 28 .

3. 3. Y si embargo, el lexicógrafo, como el gramático, no hace bien al ignorar lo que escapa a la norma, pues este mismo concepto de lo

lo que, de ser posible, sería la única manera de predecir los neologismos. Obsérvese además que "autoridad" y "norma" no son términos equivalentes, como hemos demostrado en $\S 3$. 1. El criterio de autoridad describe, en definitiva, una manera individual de emplear el sistema, no la norma.

29 M. Pidal (1945, XIII). Recuérdense las palabras de Casares citadas en la nota 26.

30 Santos incluye, por ejemplo, en su trabajo formas que no se encuentran en el DRAE92 (vgr. endemoniadamente, informativamente, socialmente, temperamentalmente, etc.).

31 Cfr. Alvar Ezquerra (1982).

32 M. A. K. Halliday $(1961,267)$ llama la atención sobre la pertinencia de no mezclar el nivel de descripción gramatical con el de descripción léxica: "For the moment it seems better to treat lexical relations, where even the identification of the items concerned by grammatical means is extremely complex, as on a different level, and to 
"normal" es algo sujeto a las leyes del tiempo. Lo que hoy nos puede parecer extraño, excepcional, puede convertirse mañana en algo común y establecido, digno de descripción gramatical y lexicográfica. "El diccionario de hoy", nos dice Menéndez Pidal, "debe acudir a las múltiples necesidades del presente, y debe prever las dificultades que el lector de mañana encontrará en nuestros escritos, llenos de voces y frases no acogidas en nuestros diccionarios por estimarlas demasiado nuevas, inconscientes y efímeras. Pero ¿quién puede distinguir en el momento actual lo que es efímero de lo que se afianzará en el idioma?"29. Evidentemente, ni del lexicógrafo ni del gramático puede exigirse que sean capaces de predecir con éxito el futuro de la lengua, aunque nada les exime de la responsabilidad de intentarlo.

\section{4. ¿DICCIONARIO DE ADVERBIOS EN -MENTE O DESCRIPCIÓN GRAMATICAL?}

4. 1. Hasta el momento hemos analizado las dificultades teóricas generales que se presentan al intentar incluir los adverbios en -mente en un repertorio lexicográfico. Ahora bien, puede entenderse que la incidencia de estas dificultades será diferente si este repertorio es un diccionario ya conformado o si, por el contrario, se trata de un glosario que sólo contiene estas unidades, en cuyo caso la misma finalidad del trabajo justificaría un tratamiento diferente de los problemas. Así, del diccionario de adverbios en -mente, por la especificidad de su objeto, podría esperarse tal vez una mayor exhaustividad en la elección de las entradas ${ }^{30}$, mientras que no parecería necesario establecer en él de manera expresa la conexión semántica con el adjetivo de la base.

En principio, tal expectativa es falsa. Considerar que el diccionario de adverbios debe ser más exhaustivo en su selección de unidades que el diccionario general lleva a considerarlo un repertorio de actuali-

require a different theory to account for them". Cfr. también Halliday (1966).

33 Cfr. los importantes trabajos para el español de Domínguez de Rodríguez Pasqués (1970), López (1977), Egea (1979), Barrenechea (1979), García-Page (1991, 1993, 1994-95), Báez San José (1994) y muchos otros que han proliferado en los últimos años y que tratan el tema bajo uno u otro aspecto. 
zaciones fácticas, en el que no impera ya el criterio de la autoridad (ni, estrictamente, el de la norma). Pero ¿viene marcado el grado de exhaustividad descriptiva por el propio objeto de la descripción o es el lexicógrafo el que lo determina? Ciertamente, no parece que exista un criterio objetivo (es decir, lingüístico) por el cual debamos entender que un repertorio lexicográfico tiene la obligación de ser "más completo" que otro. En cuanto a la posibilidad que presentaría el glosario de adverbios en -mente de prescindir de la referencia al adjetivo de la base, ya hemos expuesto más arriba (§ 2.3. 2.) nuestra opinión acerca de los lazos de necesidad que unen el adverbio en -mente con el adjetivo. Introducir este elemento en el glosario presenta ciertamente muchos problemas, pero no hacerlo supone renunciar de antemano a uno de los factores de descripción fundamentales. Confróntese a este respecto lo que se menciona más abajo a propósito del cuadro-ejemplo (nota 39). En resumen, si el diccionario de adverbios en -mente debe plantear los mismos límites metodológicos de un diccionario general, ¿qué sentido tiene proponerlo?

4. 2. Si entendemos que la exhaustividad debe darse en cuanto al grado de afinamiento descriptivo de cada lema, la cuestión se plantea en otros términos: ¿acaso compete este trabajo a la lexicografía? En nuestra opinión, el análisis integral de los adverbios en -mente, de sus propiedades sintácticas y semánticas, de sus conexiones con el adjetivo, de su estatus categorial, etc. no es tarea para la lexicografía sino para la gramática. Y aunque no se trata propiamente de negar las evidentes conexiones entre ambas disciplinas 31 , hay que establecer con precisión los límites de cada una de ellas para no cometer el error de equiparar sus resultados, pues en realidad se trata de dos niveles diferentes de estudio del lenguaje ${ }^{32}$, que responden a intereses diferentes y de los que puede decirse, en consecuencia, que tratan objetos diferen-

34 Esto sucede, por ejemplo, con económicamente, donde resulta realmente difícil deslindar entre los significados 2. y 3. 1. El primer caso se define como "Adv. m. orac. (Hablando) en términos propios de la ciencia económica. Afecta al acto mismo del decir. Económicamente, deflación e inflación, respectivamente." Es decir, se trata de un adverbio performativo. Más adelante leemos: "Adv. p. vista de perspectiva. 3. 1. (Considerado) desde la perspectiva de los principios económicos. Económicamente, la propuesta del gobierno es impresentable.” ¿No podría interpretarse igualmente 
tes. No puede extrañar por tanto que a los grandes aciertos teóricos a los que se ha llegado por medio del estudio sistemático y teórico de los adverbios en -mente ${ }^{33}$ no les corresponda el mismo éxito en el terreno de la lexicografía, puesto que lo que para el gramático se presenta como un problema puede no ser tal para el lexicógrafo y, en cualquier caso, los problemas a los que se enfrente éste no tienen por qué poder resolverse con los procedimientos desarrollados por aquél.

4. 3. El trabajo de Santos nos parece muy ilustrativo de los problemas a que se enfrenta el estudioso cuando pretende sistematizar los adverbios en -mente a base de combinar el estudio del nivel léxico con el del nivel gramatical. Por una parte, el espíritu gramatical del trabajo permite al autor afinar mucho en sus descripciones, sin embargo, en ocasiones resulta difícil acordar hasta qué punto es pertinente este afinamiento: es cuando las distinciones se vuelven tan sutiles que apenas pueden ser percibidas ${ }^{34}$. Además resulta que el grado de especialización al que llega la descripción es una opción metodológica que el au-

como performativo?.

Por su parte, las definiciones consignadas bajo 3.2. 1. y 3.2.2. vienen a significar lo mismo (el propio autor así lo reconoce), sólo que la segunda expone un mayor grado de especificidad, al seleccionar unos contextos determinados: "Adv. p. vista aspectivo. 3. 2. 1. En el aspecto económico, en lo económico [...] 3. 2. 2. Con sentido próximo al de 3.2. 1., se amalgama con verbos como apoyar, ayudar, sancionar, multar y otros parecidos reproduciendo, en combinación con el verbo un sintagma nominal en que se especifica, a la vez, la materia y la índole o el tipo de la ayuda, apoyo, etc." Repárese en que también la diferencia entre 3. 1. (Adv. p. vista "de perspectiva") y 3. 2. 1. (Adv. p. vista "aspectivo") es extremadamente sutil. (Santos 1994, 91).

35 Es decir, el hecho de que en algunos casos se tenga la perspicacia de llegar a un nivel de descripción bastante complejo no presupone necesariamente que en la descripción de otra unidad no se pase por alto algún rasgo fundamental de su significado, por ejemplo porque se trate de algún uso en el que no haya reparado (o que desconozca) el autor.

36 La descripción de los contextos verbales (colocaciones) más usuales en los que pueden aparecer las unidades es una forma útil de singularizarlas. Según Halliday (1966) el análisis de las colocaciones constituye el ámbito que corresponde al estudio del léxico.

37 Cfr. supra lo dicho para claramente. Las diferencias de significado se vinculan a la posición, interna o externa a la oración, en que se encuentra el adverbio. 
tor ni siquiera llega a controlar totalmente, pues no siempre se está en condiciones de alcanzar el mismo nivel de delicadeza en la definición de cada una de las unidades 35 .

4. 4. Un trabajo sobre los adverbios en -mente en el que se quiera describir en detalle el máximo de sus características léxicas y gramaticales, topará con la gran dificultad de tener que delimitar exactamente entre lo semántico y lo sintáctico. En una gramática aún pueden explicarse las relaciones que existen entre el significado de una unidad léxica y su función o posición en la estructura de la oración. Pero un diccionario, por definición, contempla las unidades léxicas como entes aislados, descontextualizados, a los que trata de asignar un significado. El lexicógrafo debe describir los significados de un modo lo suficientemente general como para poder dar cuenta del mayor número de contextos posibles, pero no tan abstracto que no sea capaz de singularizar cada unidad en el conjunto del léxico de la lengua ${ }^{36}$. Por otra parte, las consideraciones gramaticales que admite esta labor no deben nunca interferir en la claridad del enunciado. Para el caso de los adverbios en -mente esta afirmacion adquiere una relevancia especial, pues resulta en ocasiones muy difícil decidir cuál es el factor decisivo en la descripción: la función o funciones sintácticas o el significado que adoptan en cada caso. ¿Debe partirse de la descripción sintáctica y detallar después los distintos significados para cada función o, por el contrario, es aconsejable partir del significado y comprobar después cuáles son las funciones que puede desempeñar el adverbio con ese sentido? Con mucha frecuencia adoptar esta segunda posibilidad obliga a rectificar el significado descrito, ya que función y significado son indisolubles o, en otras palabras, la posición y el contexto determinan profundamente

38 Puede suceder que el adverbio no aparezca en el DrAE (p. e. claramente). Esta parte del análisis es prescindible, pero ilustra bien las diferentes concepciones acerca de los límites del diccionario. El problema se plantea cuando es el corpus el que no ofrece ningún ejemplo para alguno de los adverbios que sí recoge el DRAE y éste no es un término para el que sea fácil imaginar un contexto, p. e. banderizamente.

39 Esta indicación pretende facilitar el acceso al adverbio estableciendo previamente una conexión con el adjetivo. Sin embargo plantea bastantes problemas: por una parte, podría considerarse superflua, pues el diccionario de adverbios en -mente no exigiría en principio una explicación de la génesis de sus unidades, si las considera sólo a partir de haber sido ya creadas. Además, si se opta por incluirla no basta con 
los matices significativos de la unidad, hasta el punto de que un cambio en la función provoca una diferente interpretación semántica ${ }^{37}$.

4. 5. Para ilustrar lo dicho hasta ahora quisiera presentar una muestra (un lema) de mi propio intento por elaborar un diccionario de adverbios en -mente. En ella aparecen algunos de los problemas que he tratado en las líneas anteriores, especialmente los relacionados con la delimitación de los niveles del análisis. La lematización presenta en este modelo varias partes: primero se consignan las marcas semánticas que se desarrollarán después en las acepciones de la palabra. Aparece también la réplica (si la hay) de esta misma palabra en el DRAE (esta parte se justifica por el propósito contrastivo y de enmienda que tenía originariamente mi trabajo) y, finalmente, la referencia a una posible conexión semántica del adverbio con el adjetivo de la base. Por su parte, la entrada se estructura en acepciones que corresponden a las marcas semánticas del lema y que, a su vez, se subdividen en usos más diferenciados, generalmente asociados a las colocaciones preferentes del adverbio. Cada uno de estos uos se ejemplifica mediante una cita extraida de un corpus de elaboración propia.

Si presento aquí este modelo no es tanto por postular la factibilidad

COMPLETAMENTE i., $\mathbf{m}$. $\rightarrow$ lema (atestiguado en el corpus) Al lado, marcas semánticas: $\mathrm{i}=\mathrm{adv}$. de intensidad; $\mathrm{m}=\mathrm{adv}$. de modo

completamente

1. adv. m. Cumplidamente, sin que nada falte. $\rightarrow$ entrada, marca clasemática y semántica y definición del DRAE 38

hacerlo una sola vez, sino que debería especificarse junto a cada una de las acepciones del adverbio, para no dar siempre por supuesto ni que existe ni que no existe en todas ellas una conexión semántica con la base. Como se ha afirmado en repetidas ocasiones en este trabajo, no puede decirse propiamente que el adverbio no es predecible desde ninguno de los significados del adjetivo, de modo que añadir esta indicación queda como un acto intuitivo que no da fe de la compleja realidad de los hechos, pero que podría ayudar a orientarnos por ella.

40 El criterio de ordenamiento de las definiciones es el que suele adoptarse en los dic- 


\begin{tabular}{|ll|}
\hline$\rightarrow$ completo, $a$ & $\rightarrow$ el adj de la base mantiene \\
& $\begin{array}{l}\text { o no una conexión semántica } \\
\text { directa (primeras acepciones del } \\
\text { diccionario) con el adverbio: } \\
\text { la marca } \neq \text { delante del adjetivo } \\
\text { indicaría que esto no sucede }\end{array}$ \\
& $\rightarrow$ Primera definición del adv., \\
& según la marca gramatical que se \\
& considera más cercana al sentido de \\
l. Intensificador:"del todo, por (intensificador) & 40 \\
completo" & $\rightarrow$ Primer uso del adverbio como \\
& $\rightarrow$ Cita del corpus que ejemplifica \\
1. 1. Normalmente antepuesto, & \\
junto a adjetivos calificativos. &
\end{tabular}

cionarios generales: de la acepción más común a la más específica. En mi caso, este criterio estadístico está fundamentado en el corpus del que provienen todas las citas que se presentan. Pero, además, esta primera división del significado se justifica sintácticamente: con el sentido 1. el adverbio aparece junto a adjetivos y participios; con el sentido 2., junto a verbos. Acerca de la dirección en que habría que entender las relaciones entre sintaxis y semántica en cada lema, vid supra,.§4. 4.

41 La subacepciones se justifican más por criterios de colocación que por diferencias de significado. Cuanto más detallada es la descripción sintáctica, más difíciles de precisar son los rasgos semánticos distintivos, pues el contexto (verbal) los suple en parte.

42 Por supuesto, se trata de una aclaración justificada en esta palabra, no de una acepción nueva. De ahí la falta de numeración. Esta indicación es una muestra palpable de la vacilación a la que puede llegarse si se pretende afinar demasiado en la descripción: la cita hace evidente la conexión semántica entre las acepciones 1. y 2., pero el criterio sintáctico nos ha llevado a mantenerlas separadas. La necesidad que nos hemos autoimpuesto de llevar a cabo un estudio detallado en lo máximo nos obligan a establecer divisiones que no encajan bien con la realidad semántica de los hechos, donde seguramente lo que hay no es más que un continuum más o menos matizable.

43 La tiranía del corpus representa una paradoja para el estudioso, pues, en definitiva, es él quien determina su extensión y operatividad. La descripción de la lengua mediante un corpus no puede ser más que la descripción de un corpus. Obsérvese que Azcárate establece esta misma limitación para su diccionario; no así Santos para el suyo. De ahí también las grandes diferencias en el resultado.

44 Frente a ello, la propuesta de lematización para los diccionarios generales presentada 


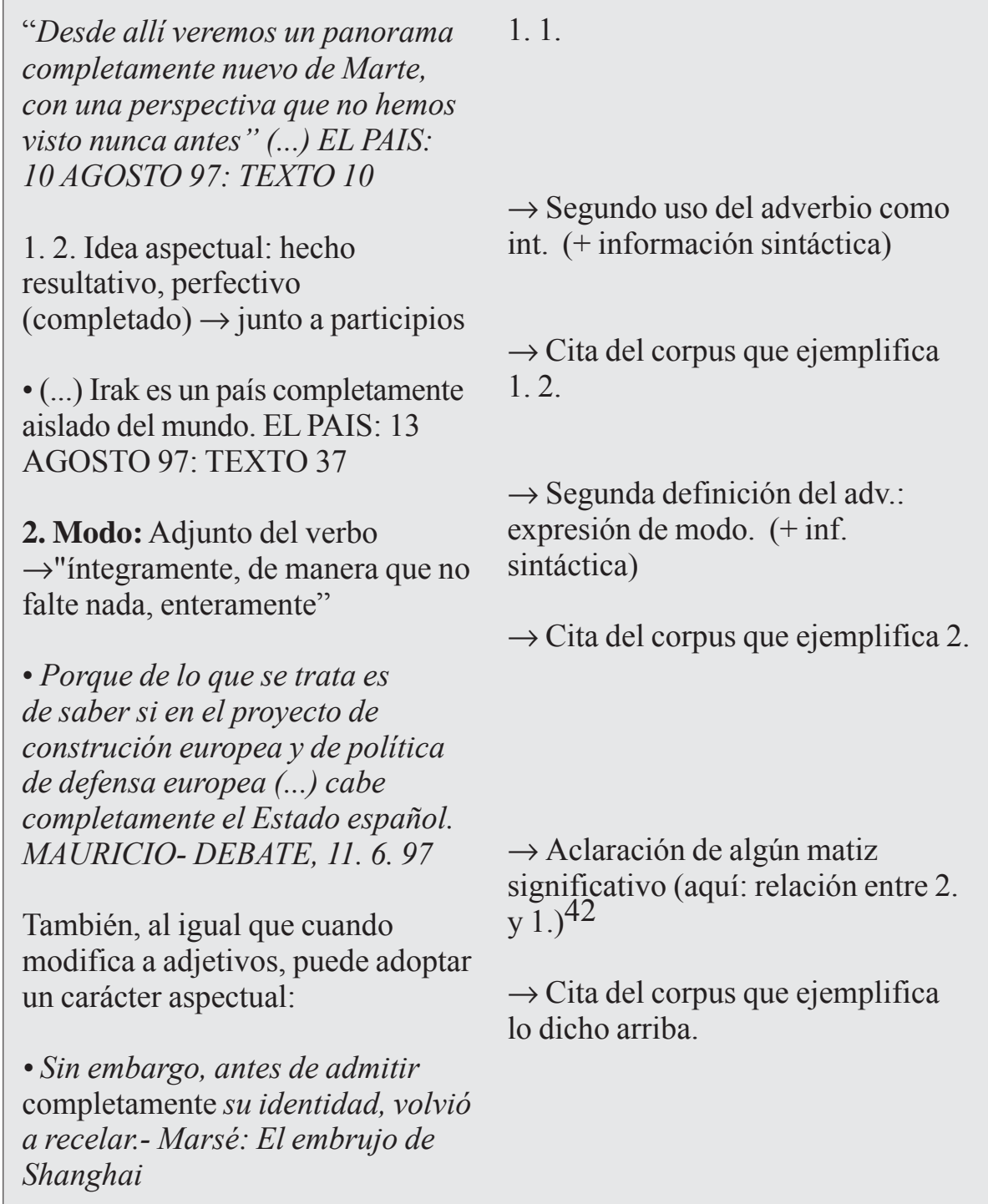

en el apartado §2. 4. no sólo es factible, sino también metodológicamente adecuada. 
de la tarea, sino más bien al contrario, por destacar las contradicciones teóricas que encierra su realización. Obsérvese que en todo momento son nuestras propias pretensiones metodológicas las que nos llevan a callejones sin salida: si pretendemos aplicar el método inductivo y otorgamos al corpus el carácter de límite extensivo del diccionario, él mismo coarta nuestra operatividad, nos obliga a rechazar aquello que, como usuarios de la lengua, sabemos real pero que no podemos atestiguar $^{43}$. Por otra parte, hay que fijar también un límite descriptivo, un nivel por debajo del cual no seguir buscando diferencias, pero este límite no lo da ya el corpus, sino que lo adopta cada uno mediante un acto decisionista. Cuando pretendemos ser exhaustivos en la descripción nos vemos obligados a establecer niveles allí donde no hay más que uso, lo que, de paso, nos plantea el problema de tener que decidir cuál de dichos niveles (el sintáctico o el semántico) tiene preferencia metodológica. En ocasiones parece prevalecer el criterio sintáctico, pero ¿qué valor tiene esto en la elaboración de un diccionario, que es en definitiva un atesorador de significados? El cuadro anterior nos coloca más cerca de responder a la pregunta que formulamos en el título: efectivamente, es factible elaborar un diccionario de adverbios en -mente. Sin embargo, estamos ya en condiciones de comprobar la mala adecuación de la pregunta al problema que se ha tratado aquí. En realidad, la cuestión que había que plantear era: ¿es metodológicamente útil, es decir, necesaria para la mejor comprensión de los adverbios en -mente la elaboración de un diccionario así? Nuestra opinión es que a esta pregunta no se puede responder más que con una negación 44 . 


\section{CONCLUSIONES.}

5. 1. En las páginas precedentes he intentado demostrar, si no la imposibilidad práctica de llevar a cabo un diccionario que incluya sólo adverbios en -mente, sí los múltiples y variados problemas que presenta esta tarea y su poca utilidad para el mejor conocimiento de estas unidades. En ningún caso esta negativa debe interpretarse como el abandono de la labor de descripción de los adverbios en -mente en los diccionarios generales. En ellos estas cuestiones no adquieren la misma relevancia pues su misma concepción como exponentes de la norma y de la autoridad lingüística les exime (parcialmente) de ser exhaustivos. Aunque, por otra parte, es cierto que los diccionarios de español han descuidado tradicionalmente esta parte del léxico, en parte por pura imitación de la actitud académica, de modo que se han mostrado incapaces de dar cuenta de la evolución semántica y sintáctica que se ha operado en los adverbios en -mente con el paso de los años, en parte por incapacidad para resolver las paradojas lexicográficas que planteaban. Esta falta puede y debe ser subsanada en el futuro. Entre las posibilidades propuestas, la que defiende la inclusión de algún tipo de marca en la microestructura del lema de la base, junto a cada acepción involucrada en el significado del adverbio, es la que hemos defendido y ejemplificado en $\S 2$. 4 .

5. 2. Los adverbios en -mente se han convertido en la actualidad en uno de los puntos de fricción entre los hechos reales, individuales, de lengua y su abstracción científica. La gramática, con su maquinaria teórica y reductora, sólo a duras penas y sólo parcialmente es capaz de dar cuenta de su naturaleza, pero en ningún caso está en condiciones de explicar lo que en mayor medida singulariza a esta clase: su productividad expresiva. Dada esta dificultad y dado que la clase adverbial en general es aún hoy una categoría mal comprendida, se ha propuesto abordar la cuestión desde la sistematicidad que ofrecen los diccionarios al uso. No es lícito entonces reprocharles a éstos el ser poco capaces de presentar un cuadro gramatical coherente de los adverbios en -mente. Ni es ésa la tarea para la que han sido diseñados ni puede acusárseles de no resolver problemas que ellos mismos no plantean. No 
puede decirse lo mismo, sin embargo, del diccionario de adverbios en -mente, pues el mero propósito de realizarlo implica una opción metodológica que termina por cuestionarse a sí misma. Por tanto, propongo mejorar las definiciones de estos adverbios en los diccionarios generales (lo cual pasa por una revisión de las definiciones de los adjetivos), incluyendo, eso sí, información sobre sus colocaciones más frecuentes, y dejar a la investigación teórica, gramatical, la descripción pormenorizada de sus características sintácticas.

\section{BIBLIOGRAFÍA}

Alvar EzQuerra, Manuel (1980): “¿Qué es un diccionario? Al hilo de unas definiciones académicas", LEA, II/1, pp. 103-118, citado por Alvar Ezquerra, M. (1993), pp. 59-72.

_ (1982): "Diccionario y gramática”, LEA, IV/2, pp. 151-212, citado por Alvar Ezquerra, M. (1993), pp. 87-143

_- (1993): Lexicografia descriptiva, Barcelona, Vox-Biblograf.

AZCÁRATE LuXÁN, Margarita (1992): Introducción al estudio de los adverbios en -mente, en español, (Tesis doctoral), Madrid, UCM-Servicio de Reprografía.

BÁEz SAN José, Valerio (1994): “Las formas en -mente en una teoría fenomenológica integrada del acto de hablar, la expresión y el esquema oracional”, $L E A, \mathrm{XVI} / 2$, pp. 229-269.

BARRENECHEA, Ana María (1979): “Operadores pragmáticos de actitud oracional: los adverbios en -mente y otros signos", en VVAA: Estudios lingüísticos y dialectológicos. Temas Hispánicos, Buenos Aires, Hachette, pp. 39-59.

Bello, Andrés (1898): Gramática de la lengua castellana, ed. de R. Trujillo, Tenerife, Instituto universitario de lingüística Andrés Bello, 1981.

CASARES, Julio (1969): Introducción a la lexicografía moderna, Madrid, CSIC. 
Corbin, Danielle (1982): "Le monde étrangere des dictionnaires (2): Sur le statut lexicographique des adverbes en -ment", Lexique, 1, pp. 25-64.

Coseriu, Eugenio (1955) "Sobre las categorías verbales ("Partes de la oración”)", en COSERIU, E. (1978): Gramática, semántica, universales, Madrid, Gredos, pp. 50-79.

(1957): "Logicismo y antilogicismo en la gramática", en Revista Nacional, 189, pp. 456-473, citado por CoSERIU, E. (1962): Teoría del lenguaje y lingüística general, Madrid, Gredos, pp. 235-260

Domínguez De RodríGuez-PASQUÉS, P. (1970): “Morfología y sintaxis del adverbio en -mente", Actas del III Congreso de Hispanistas, pp. 293-303.

Drae-92: ReAl ACADEMia EsPañola (1992): Diccionario de la Lengua Española, Madrid, Espasa Calpe.

DRAE-84: Real Academia Española (1984): Diccionario de la Lengua Española, Madrid, Espasa Calpe.

DS: VVAA (1996) Diccionario Salamanca de la Lengua Española, Madrid, Santillana

Due: Moliner, María (1960): Diccionario de Uso del Español, Madrid, Gredos; $2^{\mathrm{a}}$ ed.: 1998.

EGEA, Esteban Rafael (1979): Los adverbios terminados en -mente en el español contemporáneo. Bogotá, Publicaciones del Instituto Caro y Cuervo.

García-Page, Mario (1991): "El adverbio en -mente, Motivación contextual en formaciones léxicas «anómalas»", Anuario de Estudios Filológicos, pp. 149-181.

__ (1993): "Breves apuntes sobre el adverbio en -mente", Verba, 20, pp. 311-340.

(1994-95): "Relaciones de "solidaridad" en el adverbio en -mente", Estudios de lingüística, 10, pp. 145-163.

GonZÁLEZ GARCíA, Luis (1997): El adverbio en español, Universidade da Coruña.

Gregores, Emma (1960): "Las formaciones adverbiales en -mente", $F i$ lología, 6, pp. 77-102.

Halliday, M. A. K. (1961): "Categories of the Theory of Grammar", Word, 17, pp. 241-292.

— (1966): "Lexis as a linguistic level", en BAzell, C. E.; CATFord, J. 
C.; Halliday, M. A. K.; Robins, R. H. (eds.): In memory J. R. Firth, London and Beccles, Longmans, pp. 148-162

HAENSCH, Günther (1997): Los diccionarios de español en el umbral del siglo XXI, Universidad de Salamanca.

KARLSSON, K. E. (1981): Syntax and Affixation. The evolution of-MENTE in Latin and Romance, Tübingen, Max Niemeyer Verlag

LóPEZ, Ángel (1977): Elementos de semántica dinámica. Semántica española. Zaragoza, Pórtico, cap. 9: "El subsistema semántico de los modificadores adverbiales", pp. 139- 250

MAYORAL, José Antonio (1982): "Creatividad léxica y lengua literaria: las formaciones adverbiales en -mente", Dicenda, 1, pp. 35-53

MEnÉndez Pidal, Ramón (1945): "El diccionario que deseamos", prólogo del DGILE (=Diccionario General Ilustrado de la Lengua Española), Barcelona, nueva redacción, Barcelona, Vox-Biblograf, 1987, pp. XII-XXVIII.

MoIGNET, Gérard (1963): "L'incidence de l'adverbe et l'adverbialisation des adjectifs", TraLiLi, 1, pp. 175-194

Moreno Villanueva, José Antonio (1995): "La sufijación en -mente: su inclusión en los diccionarios del español", comunicación leída en el XIII Congreso Nacional de la Asociación Española de Lingüística Aplicada, Castellón, 26-28.4.95.

SANTOS, Luis (1994): Apuntes paralexicográficos. I.- El diccionario como pretexto, Salamanca, Gráficas Varona, reimpr. 1995.

SAPORTA, Sol (1990): "The status of spanish foms in -mente", Hispanic Linguistics, 4/1, pp. 181-183

ZAGONA, Karen (1990): "Mente adverbs, Compound Interpretation and the Projection Principle", Probus, 2/1990, pp. 1-30. 